\title{
O DIREITO COMO GARANTIA DA COESÃO SOCIAL VIA SUA EFETIVIDADE SOCIAL ENQUANTO PROPOSTA DA TEORIA DISCURSIVA DO DIREITO DE HABERMAS
}

\author{
Alcione Roberto Roani*
}

\begin{abstract}
Resumo
O objetivo deste texto é discutir a proposta de Habermas de implementação do direito, uma vez que é a partir deste processo que derivam a legitimidade e a legalidade do próprio sistema jurídico. A modernidade é um projeto inacabado, ao contrário da pós-modernidade, na qual Habermas procura estruturar o direito a partir do contexto base da razão comunicativa. Uma análise histórica reconstrutiva do direito com ênfase no caráter coercitivo e desta para uma reconstrução do direito pelo caminho do agir comunicativo, para assim redesenhar a efetividade social do sistema jurídico. Habermas visa a responder a seguinte questão: é possível a efetividade da coesão social na concepção de direito ou é o direito uma desconexão entre sistema jurídico e mundo da vida? Para Habermas há uma necessidade latente de refletir sobre estas questões em conciliação com a idéia de uma jurisdição, de uma determinação política e moral capaz de buscar um significado para a determinação da vida correta. O pluralismo e o multiculturalismo são realidades no caminho de uma justiça que, cada vez mais, necessita da participação dos seus atores para adquirir legitimidade e por que não validade (aceitação). Esta proposta de mudança na fundamentação do direito evocada por Habermas promove uma reviravolta no modo de articular o direito e, assim, o direito pode efetivar a grande aspiração da humanidade, a saber, a efetivação da liberdade.
\end{abstract}

Palavras-chave: Habermas, direito, teoria discursiva.

\footnotetext{
* Mestre em Ética e Filosofia Política pela Universidade Federal de Santa Catarina (UFSC); Graduando em Direito (UPF). Professor na Universidade Regional Integrada do Alto Uruguai e das Missões (URI) - Campus de Erechim. É autor do livro "Moral e Direito: Kant versus Hegel”. E-mail: profroani@gmail.com
} 
O ponto de partida para sedimentar sobre as bases da Faktizität und Geltung a proposta de reconstrução do direito localiza-se na própria revisão do sentido da racionalidade jurídica. Este primeiro esboço da fundamentação do direito carrega no seu âmago o caráter da crítica ao conceito weberiano de racionalidade jurídica. O problema da fundamentação do direito emerge a partir dos princípios da Filosofia do Direito de Hegel e a visão de direito de Marx, da concepção de juspositivismo de Kelsen (normativismo jurídico) e de Bobbio (ordenamento jurídico). Além destas vertentes jurídicas, há também a contribuição do pensamento pós-positivista de Dworkin (teoria do direito) e de Perelman (argumentação jurídica).

A partir destas bases e confrontando-as com o pensamento jurídico de Habermas, pretende-se demonstrar o papel da racionalidade jurídica e as suas escalas na construção da idéia de direito nas sociedades históricas e factuais. Habermas enfatiza a racionalidade dos processos institucionalizados por intermédio do direito utilizando a via da relação interna procedimental entre direito, moral e política. Este primeiro pilar da arquitetônica da reconstrução do direito é complementado por um segundo pilar fundado no papel da jurisdição e o seu vínculo com o Estado democrático de direito. Caráter este derivado da competência e da legitimidade da jurisdição enquanto controle da constitucionalidade pelo procedimento democrático. A teoria discursiva do direito de Habermas visa a demonstrar que a tendência à judicização promoveu uma colonização do mundo da vida e em conseqüência uma desconexão entre sistema jurídico e mundo da vida. Assim, surge também o terceiro pilar concretizado sobre a base da relação entre política e direito no Estado democrático de direito. Este procedimento de formação legítima do direito ressalta os princípios do Estado democrático de direito e a sua tradução a uma compreensão procedimental do direito (Habermas versus Rawls). Isso significa que a teoria discursiva do direito encontra-se diante do desafio lançado pela bioética, a saber, o de superar o gap (Jonas) em relação à questão normativa e a deficiência da moral e do direito diante de desafios como a eugenia e a biotecnologia (Dworkin).

No entanto, há uma patologia que atinge o estado democrático de direito denominada de "perda da validade jurídica", o que desencadeia sintomas como a crise do estado de direito. A proposta de Habermas é estabelecer um entrelaçamento no projeto jurídico a fim de evitar estes surtos patológicos, mas para isso é necessário analisar as condições de legitimidade do direito, que, por sua vez, exige uma reconstrução desde 
a gênese do direito. $\mathrm{O}$ objetivo da presente tese é o de redesenhar o REVISTA GRIFOS 277 direito e seu sentido de efetividade à luz da proposta de fundamentação do direito apresentada por Habermas para, depois de concretizada esta tarefa, ocupar-se efetivamente da coesão social diretamente vinculada à concepção de direito. Vínculo este demonstrado pela relação entre sistema jurídico (racionalidade jurídica e forma jurídica) e estado democrático de direito (princípio da democracia, princípio do discurso, princípio da universalização) enquanto entes fundamentais para o contexto do direito via mediação social entre as faces da facticidade e da validade.

O papel desempenhado pelo direito nas sociedades modernas pressupõe um conceito de direito que cumpra as exigências de legitimação. O ordenamento jurídico pós-convencional incorporou a necessidade de garantir a liberdade, mas desagregando-a do vínculo com as fontes metafísicas e consuetudinárias e, em função disso, resta saber então de onde emana a validade de suas pretensões, uma vez que a normatividade carece de legitimidade. Para Habermas a institucionalização do direito se realiza via ordens legítimas, que têm como pressuposto o acordo reconhecido intersubjetivamente. Isso significa que o acordo que antes era firmado sob a ótica da tradição passa a ser obtido como um acordo comunicativo alcançado pelo consenso, no qual o direito se torna o médium da tensão entre facticidade e validade.

A bioética é um exemplo disso, pois apresenta situações limítrofes com um alto nível de dificuldade de estabelecer o consenso em função da complexidade que o agir por respeito à vida humana encontra em situações como: aborto, eutanásia, distanásia, clonagem e intervenção genética. A tentativa de Habermas de estabelecer uma crítica às estruturas sociais através da sua teoria da racionalidade comunicativa é objeto de reconstrução justamente pela incorporação do elemento da racionalidade comunicativa na ação a fim de abordar as limitações e chegar ao entendimento. Os resultados destas implicações refletem no tratamento de caráter consensual da verdade e a sua aplicabilidade a problemas práticos no âmbito da bioética e do direito.

A edificação filosófica do direito procura identificar a face pluralista e a dificuldade de manter o direito coeso sob o significado da competência. Hegel foi um bom candidato ao superconceito de direito capaz de amortecer o impacto da pluralidade de perspectivas. A realidade social também é o desafio para a idéia de direito que nasce sob a proteção da doutrina kantiana, à qual Habermas demonstra uma recorrente inclinação. Mas nesta esteira há espaço também para a figura de Marx, que procura materializar a filosofia do direito hegeliana. A idéia de estado de direito burguês entra em choque com o colapso do socialismo de Estado e a evidência do que podemos denominar "imposição forçada da forma 

rias morais e da própria esfera da sociedade civil.

As sociedades contemporâneas estão permeadas pela complexidade, e a democracia, sob o aspecto da legitimação, tornou-se um discurso vazio. Não cabe mais ao direito a afirmativa de usar os óculos cor-de-rosa em relação à realidade das instituições, pois esse falso realismo desemboca em práticas jurídicas questionáveis. As instituições livres do estado democrático de direito e o seu sentido normativo procuram enfocar uma autocompreensão do direito sem recorrer à redução cientificista ou ao artificialismo. Os últimos séculos nos depositaram exemplos suficientes dos horrores de confiar em uma razão instrumental que conduz a um processo contra si mesma. Além disso, os últimos séculos nos serviram também o indigesto cardápio de uma economia orientada pelo mercado e o exagero do poder burocrático estatal. A escassez localiza-se no patamar da solidariedade social e na conservação das estruturas jurídicas democráticas. Há também um outro fenômeno subjacente a esta onda operante, a saber, a política perde a autoconsciência da orientação e o crescimento econômico acentua a disparidade social.

A base que conforta esta situação é a de sociedades complexas mergulhadas em riscos de divergência étnica, disputas atômicas, interesses internacionais e fundamentalismos. Nas "democracias" sedimentadas, prolifera o diagnóstico de uma população iludida com a realidade. A democracia continua sendo um ideal, pois a política secularizada não consegue sustentar um estado democrático de direito sem uma democracia justificada pelo radicalismo. Mas a grande perda nesse liame é endereçada ao sujeito jurídico que não pode gozar das suas liberdades subjetivas e, muito menos, dos seus direitos de cidadão. A melancolia em que o estado democrático de direito mergulhou provoca não só a derrota como também o abandono do conteúdo democrático de direito por parte do estado, geralmente justificado pelo contexto da pluralidade.

Habermas reativa este debate acerca da legitimidade do direito em sociedades pós-convencionais e pluralistas quando abandona a fundamentação do agir comunicativo pela via da complementaridade entre direito e moral e a substituiu por uma teoria processual de validade do direito na democracia. As remissões históricas estabelecem como pano de fundo para Habermas (em relação ao direito) uma situação em que se clama por um direito capaz de organizar o caos dos movimentos constitucionalistas. As várias tendências determinadas por escolas e ideologias que demarcavam as sociedades como perplexas e colonizadas 
por instituições arcaicas recheadas de autoritarismos. Toda essa situação REVISTA GRIFOS 279 era confeccionada nos alojamentos do republicanismo e do liberalismo, em que o estado democrático de direito não passava de uma mera quimera dos sistemas de governo. Os movimentos constitucionalistas (pós 1789), por outro lado, validam o direito dos tribunais constitucionais mediante a fiscalização constitucional, provocando uma deteriorização no sentido do exercício democrático do direito.

O problema é comum em duas situações, pois se negou o estado democrático de direito (enquanto instituição jurídico-política de permanente legitimação processual da validade do ordenamento jurídico pela democracia usufruída pelo povo na busca da realização de uma integração social) e no seu lugar foi adotada uma jurisprudência sem o processo legítimo com a função inibitória presente no ordenamento jurídico. Habermas pretende revitalizar o direito por meio de uma conjectura que aproxima o princípio do discurso (enquanto neutralidade deontológica) ao princípio da democracia (institucionalizador do agir). Mas o projeto de edificação de tal arquitetônica jurídica visa a sedimentar as bases de uma formação constitucionalizada do modelo discursivo (entendido também como processual de formação da opinião). A institucionalização das situações jurídicas a serem normatizadas (direitos-garantias, direitos individuais, coletivos, difusos, procedimentais, materiais, políticos) no patamar constitucional, pelo processo legal, construído legislativamente a partir de uma estrutura ampla e irrestrita a todos.

$\mathrm{Na}$ linha da legalidade para a legitimidade do estado democrático de direito, o controle da legitimidade já se faria desde a legiferação até a aplicação das leis. $\mathrm{O}$ agir discursivo é o médium lingüístico para a reconstrução da racionalidade jurídica que não pode se prender ao imediatismo prescritivo. O ordenamento jurídico é um instrumento do processo legal, legítimo e legislativo para a integração dos componentes do estado democrático de direito.

\section{A indeterminação do direito e o papel da racionalidade jurídica}

Habermas, em "Zur Rekonstruktion des historischen Materialismus" (1990), demonstra a progressiva necessidade de reformular a teoria marxiana da sociedade e, valendo-se do título de ex-integrante da Escola de Frankfurt, enfoca uma proposta de mudança do paradigma devido ao problema da despolitização da população diante da ideologia tecnológica (HABERMAS, s.d., p. 72). Em "Strukturwandel der Öffentlichkeit” (1984), Habermas se preocupa com a despolitização 
${ }^{1}$ HABERMAS, J. Conhecimento $e$ Interesse, p. 248.

${ }^{2}$ HABERMAS, J. Erkenntnis und Interesse, p. 46.

${ }^{3}$ HABERMAS, J. Theorie des kommunikativen Handelns, p. 170.

${ }^{4}$ A questão da Hermenêutica no Direito é um método ou o próprio Direito se auto-realizando como Verdade? Essa é a discussão de Habermas com Gadamer e que remonta à questão da Tradição. A Filosofia do Direito se preocupa com a questão hermenêutica (aplicação do Direito) e só neste sentido considera a Filosofia Política. da opinião pública. A preocupação é tamanha que questiona a possibilidade de um conceito de opinião pública que seja historicamente repleta de sentido. Este novo sentido de opinião pública só pode ser edificado a partir da própria mudança estrutural da esfera pública e a partir da dimensão do seu desenvolvimento (HABERMAS, 1984, p. 283).

Em "Erkenntnis und Interesse", após tecer uma crítica ao cientificismo, Habermas acaba admitindo que tal crítica se esvaziou e diante de tal fato pretende alçar uma teoria do agir comunicativo. ${ }^{1} \mathrm{~A}$ pretensão de Habermas é a de situar seu pensamento na era pós-moderna, pretende situar a teoria do conhecimento não mais como busca por uma mera ideologia tecnocrática, mas emergir uma teoria da sociedade ${ }^{2}$ sob o título de práxis social. Já em "Theorie des kommunikativen Handelns" o modelo de ação comunicativa pressupõe a linguagem como um médium de compreensão. ${ }^{3}$

Habermas enfoca a tese da vocação prática do direito como aplicação da filosofia partindo da observação da tendência à juridicização do mundo da vida. A realidade humana espelha-se no direito como meio de integração do componente social, por isso entender o homem é entender o direito diante do qual se torna possível a convivência. $\mathrm{O}$ direito sob a ótica da filosofia apresenta conseqüências práticas, pois o direito visa à aplicação com conseqüências hermenêuticas ${ }^{4}$. $\mathrm{O}$ interesse de Habermas pelo estudo crítico da sociedade manifesta-se em "Strukturwandel der Öffentlichkeit" com o objetivo de demonstrar que na esfera pública ocorrem os debates para formação da opinião pública. É preciso um novo conceito de opinião pública (HARBERMAS, 1984, p. 274) e a partir da limitação da esfera pública burguesa Habermas demonstra o que entende por público recorrendo a sua gênese nos debates judiciais pelo método histórico-sociológico (HABERMAS, 1984, p. 14-15).

Diferentemente da esfera privada, a esfera pública é aquilo que consegue aparecer. Desde o direito Romano até a Idade Média com a idéia de res publica não havia obrigatória diferença entre público e privado. Com a separação Sociedade-Estado, separam-se também as esferas pública e privada. No século XVI, "privado" significava o que era excluído do aparelho estatal, já "público" é o estado objetivado na pessoa do soberano. Assim surge uma nova categoria de burgueses que assumem o papel central em relação ao público: os funcionários da administração pública (especialmente juristas). Habermas assinala que no continente europeu a técnica do direito romano herdada é manipulada como instrumento de racionalização do intercâmbio social, e o papel dos juristas tornou-se primordial na formação da esfera pública (HABERMAS, 1984, p. 35-37). 
As funções políticas da esfera pública se caracterizam pela busca REVISTA GRIFOS 281 de legitimação. Surgem as grandes codificações do direito burguês que acima de tudo garantem a instituição da propriedade privada. Para Habermas nos países onde não havia a tradição do direito Romano começam a surgir as instituições relativas ao Direito Privado moderno (que se caracteriza pela positivação). Exemplo disso são os Códigos da Prússia (de 1794) e da Áustria (de 1811). Para Habermas nem o modelo liberal nem o socialista são adequados para o diagnóstico de uma dimensão pública que flutua entre ambas as constelações (HABERMAS, 1984, p. 167). A esfera pública perde a força de seu princípio, a publicidade crítica. Em "Strukturwandel der öffentlichkeit" Habermas analisa a conexão histórica entre o desenvolvimento capitalista e o surgimento e a queda da opinião pública liberal. Mas surgem os problemas do intervencionismo estatal e o progresso técnico-científico, resultando na tecnocracia como uma necessidade de legitimação (HABERMAS, 1990, p. 15-17). Assim o interesse guia o conhecimento, tema abordado em "Erkenntnis und Interesse".

A Declaração dos Direitos Fundamentais é a positivação do direito natural, e, por isso, Habermas observa que o isolamento positivista da razão leva ao perigo de uma sociedade exclusivamente técnica deficitária do vínculo teoria-práxis. Um sistema de dominação pode legitimar-se apelando para a racionalidade técnica e para a ideologia tecnocrática. Em "Zur Logik der Sozialwissenschaften”, Habermas pergunta pela origem desta legitimante do saber (HABERMAS, 1988, p. 49). No entanto, na obra "Faktizität und Geltung" Habermas esclarece as conseqüências do paradigma processual (método) para o direito e para a prática da política. Já em "Erkenntnis und Interesse" especificou o assunto com o objetivo de estabelecer uma análise da conexão entre conhecimento e interesse a partir da pré-história do positivismo moderno que se caracterizou pela negação da reflexão (Positivismo, Pragmatismo e Historicismo $)^{5}$.

O estado nasce com a mudança de posição do direito (antes fa${ }^{5}$ HABERMAS, J. Erkenntnis und Interesse, p. 69. miliar) para a organização de normas reconhecidas intersubjetivamente e consagradas pela tradição (o juiz não é mais o patriarca e julga não em represália ou reconstituição do status quo ante, mas julga um culpado). O nascimento do estado se explica pela estabilização eficaz de uma posição de juiz. A integração social é realizada através de relações de poder e garantida através de instituições jurídicas convencionais. As três características do direito privado burguês eram: 1) positividade; 2) legalismo; 3) formalidade.

Para Habermas o mundo da vida não é uma associação, mas a prática comunicativa cotidiana que se nutre da cooperação, da reprodução cultural, da integração social e da socialização. A cooperação 

e da moral, pois entende ainda que o direito deve ser recuperado para a filosofia. Pois, desde Hegel e Marx, o direito está marginalizado como

${ }^{6}$ HABERMAS, J. Faktizität und Geltung, p. 9.

${ }^{7}$ HABERMAS, J. Theorie des kommunikativen Handelns, p. 107.

${ }^{8}$ HABERMAS, J. Teoria de la acción comunicativa, p. 15. filosofia. ${ }^{6}$ Habermas não se coloca contra o direito como o fez Marx, vendo-o como um instrumento de mera opressão, mas pretende uma recuperação do direito. A crítica filosófica de Habermas parte da "Mudança estrutural da esfera pública" enquanto período do direito burguês, que foi um direito positivo. Para Habermas o auge do cinismo da consciência burguesa foi justamente com o positivismo jurídico. Essa mania de positivação, de tornar escrito o direito, como racionalização não acabou. No sentido ainda da ideologia como tarefa técnica tem-se hoje uma tendência à juridicização e à proliferação do direito escrito, cuja conseqüência é uma administração pública técnica, com a necessidade cada vez maior de funcionários com preparação jurídica, a chamada profissionalização do direito para a dominação burocrática dos Estados Modernos. ${ }^{7} \mathrm{~A}$ arquitetônica do edifício jurídico habermasiano começa a ser moldada a partir desta idéia de reconstrução do direito. Tal empreitada percorre a obra habermasiana a fim de crivar a fundamentação do direito a partir da teoria da ação comunicativa.

\section{A reconstrução do direito a partir dos princípios do Estado Democrático de Direito}

O objetivo da filosofia para Habermas reside em determinar os atributos que caracterizam a idéia de razão, uma vez que o tema fundamental da filosofia é justamente a razão conforme salienta em "Theorie des Kommunikativen Handelns" ${ }^{8}$. O primeiro passo desta proposta de Habermas consiste em apresentar os elementos que constituem tal racionalidade comunicativa mediante uma pragmática universal. Alcançado este objetivo, resta então um segundo, a saber, o de definir em âmbito filosófico o conceito discursivo de verdade e suas implicações na moral, no direito e na bioética.

A ação comunicativa é uma ação lingüisticamente mediada, uma vez que esta interação envolve a dimensão pragmática da linguagem. A função da dimensão pragmática é a de mapear as condições de possibilidade da ação comunicativa no mundo da vida. Ao explicitar tais condições de possibilidade da ação comunicativa, que também caracteriza a racionalidade comunicativa, Habermas enuncia quatro pretensões de validade ao princípio do discurso, a saber: a) verdade; b) retitude; c) veracidade; d) inteligibilidade. O cumprimento destas pretensões é 
pré-requisito para que haja ação comunicativa e em conseqüência ocorra o consenso. No entanto, há a necessidade da observância também do princípio do discurso, no qual Habermas anuncia que nada pode ser reivindicado como válido a não ser que esteja fundamentado racionalmente mediante argumentos.

Neste sentido, o significado de verdade é definido no interior da própria ação comunicativa sob a égide do consenso. Já o consenso, sob o slogan de verdade, é uma tarefa constante ao mesmo tempo em que exige um caráter pragmático da verdade, ou seja, a natureza da verdade. Este critério de verdade apresentado pela sua natureza é concebido conforme o que diz respeito: a) à ética, na qual é estabelecido a partir da reflexão sobre as condições de possibilidade da ação comunicativa, e que neste âmbito implicam necessariamente o princípio da universalização; as condições de possibilidade da ação comunicativa são um fundamento suficiente tanto para o princípio da universalização quanto para as questões da verdade; b) ao direito, no qual diz respeito às regras jurídicas, pois o princípio da democracia é deduzido da racionalidade comunicativa e da forma jurídica. Este é o critério e fundamento para estabelecer uma legitimidade do direito; c) à bioética, na qual visa a deslumbrar até que ponto a biologia pode influenciar no comportamento e na existência humana. O objetivo é esclarecer as implicações entre o aspecto biológico e as determinações políticas, éticas e jurídicas.

O objetivo é demonstrar que esta perspectiva de fundamentação da ética, do direito e da bioética na ótica lingüística responde a algumas das objeções ${ }^{9}$ endereçadas às premissas metafísicas (eu inteligível). Após apresentar as condições de possibilidade da ação comunicativa integrar discursos éticos, jurídicos e bioéticos na dimensão consensual da verdade, resta ainda um segundo passo em direção à exposição das condições de possibilidade de fundamentação da ação comunicativa. Estas condições de possibilidade da ação comunicativa necessitam ser aceitas por todos aqueles que buscam entendimento a fim de que o mesmo ocorra. Habermas, ao utilizar o argumento da contradição performativa a ser evitada (argumento este desenvolvido por Apel), procura demonstrar que o argumento daquele que argumenta, ao fazê-lo, já aceita certas condições que não pode negar sem contradição (a performativa) e que também não pode provar dedutivamente sem petição de princípio (petitio principi) (DUTRA, 2005). A discussão originada a partir deste argumento, entre Apel e Habermas, trata de apresentar a prova filosófica para as condições de possibilidade da ação comunicativa (da racionalidade comunicativa).

A racionalidade comunicativa é definida pela pragmática, que reconstrói as regras universais e todos aqueles pressupostos necessários para o entendimento ou consenso, pois "a base de validade do discurso
${ }^{9}$ Algumas destas objeções são as que Hegel endereçou à moral kantiana (Roani, 2006). 
${ }^{10}$ HABERMAS, J. Teoria de la acción comunicativa, p. 208.

${ }^{11}$ HABERMAS, J. Teoria de la acción comunicativa. Complementos y estúdios previos, p. 15.

12 KANT, I. Crítica da razão prática, B 294. tem, para um ser vivo que se mantenha nas estruturas de uma comunidade fundada na linguagem cotidiana, o caráter vinculante de pressupostos gerais e inevitáveis" (HABERMAS, 1990, p. 157). Habermas salienta que "as quatro pretensões de validade devem ser necessariamente cumpridas para o sucesso de um ato ilocucionário e que tem que se cumprir para se chegar a um acordo comunicativo". ${ }^{10}$ Ora, com a pragmática Habermas pretende enfocar dois quesitos fortes: a universalidade e a necessidade, e isso só é possível por meio da reconstrução das condições de entendimento.

A edificação deste projeto representa tornar possível o conceito de racionalidade comunicativa embutido no uso da linguagem definido e comprovado na busca pelo entendimento e do consenso. Necessariamente a linguagem está voltada para o entendimento, pois todo o ato de fala reivindica validade. No entanto, Habermas recorre a uma filosofia transcendental para investigar os pressupostos da comunicação. Esta noção de transcendental é compreendida como "estrutura conceitual que se repete em todas as experiências coerentes, ainda que não fique refutada a afirmação de sua universalidade e necessidade". ${ }^{11}$

A tarefa da filosofia é determinar a concepção mínima de racionalidade, segundo Habermas, "a razão comunicativa não passa certamente de uma casca oscilante - porém, ela não se afoga no mar das contingências, mesmo que o estremecer em alto mar seja o único modo de ela 'dominar' as contingências" (HABERMAS, 1990, p. 181). Neste sentido, não se trata de uma razão como a pensada por Kant na "Crítica da razão prática", enquanto "uma ilha fechada pela natureza mesma dentro de limites imensuráveis". ${ }^{12}$ Mas do próprio sentido kantiano de uma "autoridade indeterminantemente legisladora”, da qual Wittgenstein, que considera a filosofia uma doença da qual era necessário curar-se, afirma: “a filosofia é uma luta contra o enfeitiçamento do nosso entendimento pelos meios de nossa linguagem” (WITTGENSTEIN, 1979, p. 109).

Mas o próprio Wittgenstein diminui este atenuante patológico alçado sobre a filosofia, ao afirmar que a mesma é também atividade terapêutica. Ora, neste sentido, a filosofia é dispensável para fundamentar as atividades humanas, pois as instituições e instâncias jurídicas, morais e bioéticas não precisam de uma "Crítica da razão pura" para fundamentá-las, uma vez que funcionam e não necessitam de esclarecimento filosófico. No entanto, ao resgatar o sentido terapêutico, a filosofia assume uma tarefa imprescindível, a de esclarecer as confusões das quais é autora e que na consciência do indivíduo se apresentam como posturas céticas e críticas em relação a valores e a questões como o positivismo jurídico, a justiça, a moral, a bioética, a biotecnologia, a eugenia, a intervenção genética. 
Cabe salientar que o que determina a tarefa filosófica é a questão do conhecimento e da ética, pois as questões filosóficas tratam do mundo da vida (do direito, da ética, da bioética) e, por isso, o "tema fundamental da filosofia é a razão". ${ }^{13} \mathrm{O}$ mundo da vida serve de base para a aplicação do princípio da universalização, dado que o mesmo fornece os conteúdos para os discursos práticos que não estão acima do princípio do discurso. Não significa que a ética e a teoria crítica estejam fundamentadas no mundo da vida, pois a justificação de ambas é feita de forma discursiva. O papel fundamental do mundo da vida, na filosofia de Habermas, é o de complementar o conceito de racionalidade comunicativa com a função de objetivar a racionalidade comunicativa, pois é através das suas estruturas que o indivíduo é socializado. Portanto, sistema jurídico e mundo da vida são duas estruturas acima de tudo sociológicas.

A racionalidade comunicativa e a pragmática universal para Habermas visam a expressar duas teses: a) de que a todo ato de fala está inerente o telos do acordo (HABERMAS, 1990, p. 27); b) o entendimento é um processo de obtenção de um acordo. ${ }^{14} \mathrm{~A}$ partir disso, Habermas tenta compreender a pragmática universal como a "tarefa de identificar e reconstruir condições universais do entendimento possível".$^{15}$ A proposta é de com a pragmática universal reconstruir a base de investigação universal da validade de fala e responder a seguinte questão: "como é possível a utilização da linguagem orientada ao entendimento?”. ${ }^{16}$ A função da pragmática ${ }^{17}$ é de identificar as condições de possibilidade do entendimento, da razão comunicativa.

Em sua pragmática Habermas parte da teoria dos atos de fala de Austin, pois a tarefa da pragmática é a de explicitar o conceito de racionalidade comunicativa a partir da distinção realizada por Austin entre ilocução e perlocução (o emprego da linguagem orientada para o entendimento é o modo original de emprego da linguagem). O importante da teoria dos atos de fala para a pragmática universal de Habermas é a constatação de que o ato de fala é uma ação. Habermas traduz o conceito de força ilocucionária ${ }^{18}$, realçada por Austin, como pretensão de validade. Logo, estas pretensões de validade exigem um reconhecimento intersubjetivo e necessitam estarem fundamentadas em boas razões. $\mathrm{O}$ ato de fala pressupõe assim a condição de aceitabilidade, e o entendimento tem por sustentação as razões que no caso do conhecimento (verdade) são apresentadas pelo discurso teórico (verdade) e prático (retitude). A ética, a bioética e o direito apresentam a racionalidade comunicativa com base na força do melhor argumento em busca da retitude e da verdade. ${ }^{19}$ A teoria dos atos de fala tem por objetivo classificar o caráter performativo das emissões que é igual à força ilocucionária que por sua vez fixa o modo de conteúdo emitido. ${ }^{20}$
REVISTA GRIFOS 285

${ }^{13}$ HABERMAS, J. Teoria de la acción comunicativa (I), p. 15.

${ }^{14}$ HABERMAS, J. Teoria de la acción comunicativa (I), p. 369.

${ }^{15}$ HABERMAS, J. Teoria de la acción comunicativa. Complementos y estúdios previos, p. 299.

${ }^{16}$ HABERMAS, J. Teoria de la acción comunicativa. Complementos y estúdios previos, p. 417.

${ }^{17}$ A função da lingüística é tratar da geração de orações conforme as regras da gramática, já a pragmática trata do emprego de orações (das emissões) conforme regras que estabelecem a base à fala direcionada ao entendimento.

${ }^{18}$ A classificação dos atos de fala em função da sua força ilocucionária para Austin é representada por: veriditivos, exercitivos, comissivos, comportamentais e expositivos (AUSTIN, 1990, p. 25).

${ }^{19}$ HABERMAS, J. Teoria de la acción comunicativa (II), p. 106.

${ }^{20}$ HABERMAS, J. Teoria de la acción comunicativa (I), p. 332. 
286 REVISTA GRIFOS

${ }^{21} \mathrm{O}$ ato de fala é constituído por uma dupla estrutura: a parte ilocucionária e o componente proposicional.

${ }^{22}$ HABERMAS, J. Teoria de la acción comunicativa (I), p. 30. Tradução do autor.
A força ilocucionária do ato de fala reside na sua capacidade de estabelecer uma relação interpessoal, fixando uma função comunicativa (significado pragmático) em relação ao conteúdo emitido ${ }^{21}$. Em qualquer ato de fala os participantes precisam se comunicar, e a pragmática serve para reconstruir o sistema de regras que um falante precisa cumprir. As regras são necessárias para o consenso, pois são as condições de possibilidade para tal acontecer.

No início da Theorie des Kommunikativen Handelns, ao afirmar que a tema fundamental da filosofia é a razão, Habermas estabelece também as condições formais da racionalidade comunicativa, anunciadas conjuntamente com a pragmática universal. $\mathrm{Na}$ racionalidade comunicativa "o mundo só se torna objetivo pelo fato de ser reconhecido e considerado com uno e o mesmo mundo para uma comunidade de sujeitos capazes de linguagem e ação". ${ }^{22}$ A racionalidade comunicativa se define como um sistema de pretensões de validade e disposições de sujeitos capazes de linguagem. É por via da pragmática que a racionalidade comunicativa encontra discursivamente o entendimento. No entanto, uma ação comunicativa deve cumprir as seguintes condições indispensáveis para o entendimento: “ $1^{\mathrm{a}}$ ) o cumprimento das quatro pretensões de validade; $2^{\text {a }}$ ) a resolução discursiva destas pretensões [o princípio do discurso]; $3^{\mathrm{a}}$ ) o princípio da racionalidade comunicativa sobre a estratégica" (DUTRA, 2005, p. 57). Apesar do entendimento estar inerente ao ato de fala, qualquer falante que queira argumentar como participante de uma argumentação não pode deixar de reconhecer que reivindica validade para as afirmações pelo princípio do discurso. A conseqüência primeira da "Teoria do agir comunicativo" é a de ressaltar que a linguagem preenche três funções: a) reprodução cultural ou de presentificação das tradições; b) integração social ou coordenação dos planos de diferentes atores na interação social; c) função de socialização da interpretação cultural das necessidades.

Ao aplicar a teoria da racionalidade comunicativa ao direito, Habermas constrói uma teoria discursiva do direito, na qual busca dirimir a tensão existente entre facticidade e validade, atribuindo significado e verdade à linguagem do direito. A pretensão habermasiana reside na dimensão da validade do direito na qual o problema da sua legitimidade necessita ser esclarecido a partir da relação com a legalidade. O problema que assombra o direito é justamente o da legitimidade, uma vez que a relação interna da legalidade entre coerção e liberdade é que determina a estabilidade da juridicidade. É desta relação que emerge a pretensão de validade do ordenamento jurídico, que sob os auspícios da coerção garante a liberdade. As normas jurídicas sob a ótica da legalidade apresentam um aspecto dúbio, pois elas podem ser observadas pelo respeito a 
elas, ou seja, uma ação heterônoma em stricto senso à legalidade; ou podem ser observadas pelo respeito à lei, ou seja, por uma ação autônoma de respeito à lei não por ela mesma, mas por $\operatorname{dever}^{23}$. Assim, a validade do direito apresenta-se enquanto validade social (fática) referente à sua eficácia (adesão à prescrição) sustentada pela garantia que o direito possui do aparato do monopólio da força pelo estado. Esta forma jurídica de proceder substitui as formas arcaicas de sociabilidade enraizadas nos costumes, o que garante a liga da coesão social.

A legitimidade das normas jurídicas é medida por via da racionalidade do processo legislativo, na qual cabe a justificação do patamar de cunho ético (moral) e consuetudinário. A legitimidade, validade jurídica, brota da "resgatabilidade discursiva de sua pretensão de validade normativa". ${ }^{24}$ Neste patamar, a legitimidade jurídica independe da sua eficácia, pois a validade do ordenamento jurídico não se prende ao consenso factual depositado na força consuetudinária e secular. No entanto, a legitimidade do ordenamento jurídico é que garante a validade social e também a obediência fática dos ordenamentos jurídicos. Pois o ordenamento jurídico carrega no seu âmago já a pretensão à legitimidade, e esta é a logomarca da fundamentação racional advinda do resgate racional promovido em relação às pretensões de validade. É desta reformulação que advém uma contundente advertência segundo Habermas, a de que enquanto o direito positivo não estiver assentado sobre as bases legítimas fica à deriva do puro arbítrio, pois "os usos e o mero costume precisam estabilizar uma ordem jurídica substantiva, e isso se torna tanto mais imperioso quanto mais fraca for a sua legitimidade"25.

Este é o momento mais íntimo do direito, pois a sua validade fática e a legitimidade representam para o membro da comunidade jurídica uma dupla relação com a norma jurídica: objetiva e performativa ${ }^{26} \mathrm{O}$ agente membro da comunidade jurídica deseja pautar as suas ações por via de um enfoque objetivador a fim de obter conformidade em seus atos; neste caso, a norma também é interpretada como um obstáculo fático na ótica da sanção advinda da transgressão, pois a ação ilícita promove uma consequeência jurídica. Do outro lado da moeda, o mesmo membro que guia sua busca pelo entendimento comunicativo passa a gestar um sentido deontológico para a ação, e a norma passa a ser uma guardiã da liberdade. Dessa forma,

[...] o curioso é que a validade jurídica de uma norma significa apenas que está garantida, de um lado, a legalidade do comportamento em geral, no sentido de uma obediência a norma, a qual pode, em certas circunstâncias, ser imposta por meio de sanções e, de outro lado, a legitimidade da própria regra, que torna possível em qualquer momento uma obediência a norma por respeito a $l \mathrm{li}^{27}$.
REVISTA GRIFOS 287

${ }^{23}$ Kant (1986).

${ }^{24}$ HABERMAS, J. Faktizität und Geltung, p. 50.

${ }^{25}$ HABERMAS, J. Faktizität und Geltung, p. 50-54.

${ }^{26}$ HABERMAS, J. Faktizität und Geltung, p. 51.

${ }^{27}$ HABERMAS, J. Faktizität und Geltung, p. 52. 
O direito estrutura-se como um ordenamento que supõe, ao mesmo tempo, normas observáveis pelo receio embutido na sua transgressão e normas observáveis pelo reconhecimento racional das suas prescrições. Esta dança apresenta conseqüências denominadas por Habermas de pós-metafísicas e que manifestam a necessidade de uma exigência racional de legitimidade do direito a fim de preservar a dupla coerção/liberdade. Para isso, Habermas conta com uma perspectiva

${ }^{28}$ HABERMAS, J. Teoria de la acción comunicativa. Complementos y estúdios previos.
${ }^{29}$ HABERMAS, J. Faktizität und Geltung, p. 40.

${ }^{30}$ HABERMAS, J. Faktizität und Geltung, p. 46.

${ }^{31}$ HABERMAS, J. Faktizität und Geltung, capítulo III.

${ }^{32}$ HABERMAS, J. Faktizität und Geltung, p. 53. discursiva que remete ao conceito de racionalidade comunicativa ${ }^{28} \mathrm{e}$, nesta perspectiva, estende a teoria consensual da verdade à ética (HABERMAS, 1989). Em relação à teoria consensual da verdade no direito, é apresentada, de modo especial, em "Faktizität und Geltung" (capítulo III, intitulado: "Para a reconstrução do direito"), no qual Habermas acrescenta ao título a idéia de "sistema dos direitos" e apresenta a filosofia do direito como condição de legitimidade do ordenamento jurídico. No capítulo seguinte, com o mesmo início de título, Habermas acrescenta "princípios do estado de direito", no qual apresenta os fundamentos da filosofia política (direito, poder e estado) e as condições de possibilidade de seu exercício a partir da racionalidade comunicativa.

Com a teoria do agir comunicativo, Habermas visa a atribuir operacionalidade aos conceitos fundamentais da atividade jurídica. Tal preocupação fica evidenciada quando questiona:

[...] o ponto de referência é dado pelo problema: como é possível surgir ordem social a partir dos processos de formação de consenso que se encontram ameaçados por uma tensão explosiva entre faticidade e validade? No caso do agir comunicativo, a dupla contingência, a ser absorvida por qualquer formação de interação, assume a forma especialmente precária de um risco de dissenso, sempre presente, embutido no próprio mecanismo do entendimento, ainda mais que todo dissenso acarreta elevados custos para a coordenação da ação ${ }^{29}$.

O risco do dissenso no direito é sociologicamente lembrado no mundo da vida quando o direito é interpretado como meio de integração social. Para Habermas o direito ambiciona resolver o problema de "como integrar socialmente mundos da vida em si mesmos pluralizados e profanizados" 30 .

Por isso, pretende demonstrar que direito e moral coabitam ${ }^{31}$, e esta idéia de complementaridade visa a resolver o problema da relação entre faticidade e legitimidade. Nas formas de vida arcaica, havia um zelo pela fusão entre faticidade e validade, o que no pós-iluminismo transforma-se em tensão. $\mathrm{O}$ direito necessita deduzir a pretensão de legitimidade a partir do agir de seus atores (cidadãos), dado que "a premissa para a coerção jurídica é deduzida de uma expectativa de legitimidade". ${ }^{32}$ 
O direito perde seu poder de integração social, de coesão, quando a positividade estabelece a legitimação e assassina a idéia de solidariedade social. Habermas, valendo-se desta idéia de legitimação, procura introduzi-la no direito quando: a) analisa as proposições jurídicas como atos de fala (isso implica a aceitação de certos pressupostos como o ato de justificar e de fundamentar o ato proferido ${ }^{33}$; b) quando as condições políticas derem conta da eficácia do direito, pois a filosofia do direito não é mero patrimônio do filósofo, o que também não o impede de analisar o direito ${ }^{34}$.

\section{A teoria discursiva do direito}

Para Habermas "a sociedade tem de ser integrada, em última instância, através do agir comunicativo". ${ }^{35}$ Assim, promove a integração da ação estratégica orientada pelo interesse com o cunho históricosociológico (realismo político e factual). O conceito sociológico de direito busca considerar o princípio do direito com o estado constitucional (normatividade da democracia e democracia). Por este viés, a racionalidade comunicativa representa o questionamento sobre as proposições com o objetivo de chegar ao consenso. Apesar de ser um processo falível, conforme salienta Habermas, ao alertar para o risco de desvalorização dos argumentos ${ }^{36}$. Mas avança em relação ao modo de vida tradicional em que o risco de dissenso já está embutido na dimensão da validade. Neste caso, há uma tensão entre idéia e realidade, já em relação ao dissenso, vislumbrado na racionalidade comunicativa, é decorrente da interpretação da validade (Gültigkeit, ou a verdade que se mostra para nós - Geltung $)^{37}$.

O direito, dentre outras funções, também desempenha a de amortecer as instabilidades das formas de vida ${ }^{38}$, pois os indivíduos se orientam por pretensões de validade que visam a manter a ordem social desde que se mantenham pelo reconhecimento de pretensões de validade normativa. A visão sociológica de Habermas pretende dar conta da integração social pela via do agir comunicativo, ${ }^{39}$ na qual demonstra a necessidade de a força social integradora estar revestida pela validade. A reconstrução da idéia de direito é vital para o próprio direito resolver o problema promovido pela coação do direito privado ${ }^{40}$. Essa espiral inicia quando o direito natural cede lugar para o direito positivo e, a partir deste, faz-se uso da força de forma legítima sob o monopólio do estado. Uma idéia com raízes advindas de Kant, em que o conceito de legalidade busca explicar o modo complexo de validade do direito a partir dos direitos subjetivos, no qual a validade jurídica estabiliza a relação entre validade e faticidade (liberdade e coerção). Habermas

REVISTA GRIFOS 289

\author{
${ }^{33}$ HABERMAS, J. Faktizität und \\ Geltung, p. 17. \\ ${ }^{34}$ HABERMAS, J. Faktizität und
Geltung, p. 9.
}

${ }^{35}$ HABERMAS, J. Faktizität und Geltung, p. 45. ${ }^{36}$ HABERMAS, J. Faktizität und
Geltung, p. 57.

${ }^{37}$ HABERMAS, J. Faktizität und Geltung, p. 32 .

${ }^{38}$ HABERMAS, J. Faktizität und Geltung, p. 32.

${ }^{39}$ HABERMAS, J. Faktizität und Geltung, p. 45.

${ }^{40}$ HABERMAS, J. Faktizität und Geltung, p. 47. 

vista moral, pois a validade normativa das regras necessita de reconheci-

${ }^{41}$ HABERMAS, J. Faktizität und Geltung, p. 95.

${ }^{42}$ HABERMAS, J. Faktizität und Geltung, p. 50.

${ }^{43}$ HABERMAS, J. Faktizität und Geltung, p. 52.

${ }^{44}$ HABERMAS, J. Faktizität und Geltung, p. 94.

${ }^{45}$ HABERMAS, J. Faktizität und Geltung, p. 113.

${ }^{46}$ HABERMAS, J. Faktizität und Geltung, p. 60. mento não coativo porque o interesse não é capaz de produzir uma ordem social. ${ }^{41} \mathrm{~A}$ dupla validade do direito se explica por sua validade social (Geltung) e pela sua legitimidade (Gültigkeit) ${ }^{42}$.

$\mathrm{O}$ direito ergue pretensões de validade normativa que implicam reconhecimento racional (obediência pelo respeito) e, por outro lado, mostra a necessidade do direito positivo se legitimar ${ }^{43}$. Em relação à validade do direito há uma interação entre faticidade e validade, mas o direito pretende garantir a liberdade e a legitimidade, e, a fim de resolver este impasse, o direito moderno adota o princípio da democracia. A positividade do direito adota a idéia de que há a aceitação racional da norma pelo indivíduo autônomo como lei de liberdade por via do processo democrático. Assim, o direito só consegue garantir a força integradora se os indivíduos puderem se considerar autores desta regra. A conseqüência imediata é de que a integração social se torna um fardo pesado para o direito. Dessa forma, Habermas pretende incorporar teorias filosóficas da justiça e teorias sociológicas do direito a fim de observar o direito sem "correr o risco de ficar cego". ${ }^{44}$

O conceito fundamental do direito, a saber, o de legitimidade, estabelece uma relação não promíscua com a filosofia do direito e a sociologia do direito, a fim de esclarecer a relação entre "os direitos que os cidadãos têm de atribuir uns aos outros, caso queiram regular legitimamente sua convivência com os meios do direito positivo". ${ }^{45} \mathrm{O}$ direito, que para Habermas porta uma dupla identidade (moral e política ou filosofia e sociologia), também não pode fundar-se apenas na contingência da decisão e esquecer a integração, referindo-se ao direito positivo.

$\mathrm{O}$ direito regrado unicamente pela autoridade e pelo costume gesta um paradoxo em relação ao fardo da integração social. O direito positivo, apoiado nesta idéia, procura uma saída para o problema e que se constitui em uma comunicação não circunscrita. Se nas sociedades tradicionais a convicção pagava o preço de uma limitação à comunicação, nas sociedades pós-tradicionais, a convicção da sanção também implica a separação da faticidade da validade jurídica. A garantia de um mínimo de integração social, ou a possibilidade da norma manterse somente pela sanção, determina que tanto a positividade do direito quanto sua legitimidade façam jus à comunicação não circunscrita. $\mathrm{O}$ direito pode funcionar como antídoto para o dissenso quando estabiliza os riscos possíveis de dissenso e como patologia quando a este risco estiver submetido, considerando que o paciente seja a integração social, ou melhor, legitimidade e positividade ${ }^{46}$. Assim, a idéia de estado de direito visa a estabilizar a idéia de poder político, transformando-se 
em um estado de direito democrático (demokratischen Rechtsstaats). Esta REVISTA GRIFOS 291 relação permite ao direito o contato com a solidariedade, com o mercado e com o estado. O direito continua a oferecer a legitimidade, mas sob a dualidade do idealismo constitucional e a realidade econômica enquanto forma de distribuição desigual do poder social.

A dedução do princípio da democracia pressupõe a racionalidade comunicativa, pois de tal entrelaçamento surgem a argumentação e a forma jurídica. A parte central da filosofia do direito de Habermas é composta pela interconexão entre princípio do discurso, forma jurídica e princípio da democracia. Esta é a base constituinte do denominado sistema de direitos, conforme salienta Habermas:

[...] o princípio da democracia resulta da interligação que existe entre o princípio do discurso e a forma jurídica. Eu vejo este entrelaçamento como uma gênese lógica de direitos, a qual pode ser reconstruída passo a passo. Ela começa com a aplicação do princípio do discurso ao direito a liberdades subjetivas de ação em geral - constituinte da forma jurídica enquanto tal e termina quando acontece a institucionalização jurídica de condições para um exercício discursivo da autonomia política, a qual pode equipar retroativamente a autonomia privada, inicialmente abstrata, com a forma jurídica. Por isso, o princípio da democracia só pode aparecer como núcleo de um sistema de direitos. A gênese lógica destes direitos forma um processo circular, no qual o código do direito e o mecanismo para a produção do direito legítimo, portanto o princípio da democracia, se constitui de modo co-originário. ${ }^{47}$

A forma jurídica, que pressupõe a distinção entre direito e moral, carrega um certo sentido kantiano em seu âmago, uma vez que ela é constituída pela liberdade subjetiva de ação e pela coação (DUTRA, 2005 , p. 225). O princípio do discurso advém do conceito de racionalidade comunicativa e é apresentado da seguinte maneira: "D: são válidas as normas de ação as quais todos os possíveis atingidos poderiam dar o seu assentimento, na qualidade de participantes de discursos racionais". ${ }^{48}$ A finalidade do discurso é a de chegar ao consenso, mas o ponto mais relevante não é alcançá-lo, porém consegui-lo dentro das disposições de ânimo, e isso significa que para Habermas se "deveria falar de uma teoria discursiva da verdade em vez de uma teoria consensual da verdade" ${ }^{49}$ Esta formulação neutra do princípio do discurso visa a enfocar a comunicação caracterizada pela argumentação, por isso a finalidade de um discurso é o consenso. Há um conjunto de proposições anunciadas por Alexy (1989) que sintetizam o princípio e com a qual Habermas concorda (HABERMAS, 1989, p. 109), a saber:

${ }^{47}$ HABERMAS, J. Faktizität und Geltung, p. 158.

${ }^{48}$ HABERMAS, J. Faktizität und Geltung, p. 142.

${ }^{49}$ HABERMAS, J. Faktizität und Geltung, p. 135. 
${ }^{50}$ HABERMAS, J. Faktizität und Geltung, p. 145.

${ }^{51}$ HABERMAS, J. Faktizität und Geltung, p. 159.

${ }^{52}$ HABERMAS, J. Faktizität und Geltung, p. 160.
1. É lícito a todo sujeito capaz de falar e agir participar de Discursos. 2. a) É lícito a qualquer um problematizar qualquer asserção. b) É lícito a qualquer um introduzir qualquer asserção no Discurso. c) É lícito a qualquer um manifestar suas atitudes, desejos e necessidades. 3. Não é lícito impedir falante algum, por uma coerção exercida dentro ou fora do Discurso, de valer-se de seus direitos estabelecidos em 1 e 2. (ALEXY, 1989).

Em relação à aplicação do princípio do discurso à moral e ao direito ocorre de dois modos: a) pelo princípio da universalização ["se as conseqüências e efeitos colaterais, que previsivelmente resultarem de uma obediência geral da regra controversa para a satisfação dos interesses de cada indivíduo, podem ser aceitos sem coação por todos” (HABERMAS, 1989, p. 116)] ; b) princípio da democracia ["somente podem pretender validade legítima as leis jurídicas capazes de encontrar o assentimento de todos os parceiros do direito, num processo jurídico de normatização discursiva" $\left.{ }^{50}\right]$. Para Habermas trata-se de institucionalizar juridicamente os pressupostos comunicativos a fim de conferir legitimidade ao processo de normatização. No princípio da democracia, o discurso assume uma figura jurídica, e da interligação entre princípio do discurso e forma jurídica surge o sistema de direitos. Este sistema de direitos (direitos fundamentais) gera o código jurídico, que diferentemente da forma jurídica define o status de pessoa de direito pela legitimidade.

Assim, não pode haver direito legítimo sem os referidos direitos, conforme segue:

(1) Direitos fundamentais que resultam da configuração politicamente autônoma do direito a maior medida possivel de iguais liberdades subjetivas de ação; (2) Direitos fundamentais que resultam da configuração politicamente autônoma do status de um membro numa associação voluntária de parceiros do direito; (3) Direitos fundamentais que resultam imediatamente da possibilidade de postulação judicial de direitos e da configuração politicamente autônoma da proteção jurídica individual; (4) Direitos fundamentais a participação, em igualdade de chances, em processos de formação da opinião e da vontade, nos quais os civis exercitam sua autonomia política e através dos quais eles criam direito legítimo"; "51 "(5) Direitos fundamentais a condições de vida garantidas social, técnica e ecologicamente, na medida em que isso for necessário para um aproveitamento, em igualdade de chances, dos direitos elencados de (1) até (4). ${ }^{52}$

Os direitos de 1 a 3 autorizam os indivíduos a fazerem uso das liberdades subjetivas de ação. Neste caso, o princípio do discurso garante a legitimidade aos direitos de número 1, pois a forma jurídica não os garante. $\mathrm{O}$ valor eqüitativo destes direitos gera um processo 
democrático. Para Habermas o conceito de lei pressupõe uma idéia errônea de que no conceito de direito já está pressuposta a idéia de igual tratamento ${ }^{53}$. Neste sentido, o conteúdo normativo do direito apresenta-se na forma gramatical de mandamentos que carecem de validade, mas isso deve seguir uma aceitabilidade racional que advém do discurso $0^{54}$. Para Habermas o princípio do discurso tenta manter a argumentação como neutra em relação à moral e ao direito para tornála aceitável por via do discurso. Ao institucionalizar o princípio do discurso pela forma jurídica, surgem os direitos de número 4 e, assim, os sujeitos de direitos passam da condição de destinatários de direitos para a de autores de direitos ${ }^{55}$. Aqui ocorre uma das mais importantes transformações do direito segundo Habermas, a do princípio do discurso em princípio da democracia. A jurisdição garante a aplicação, ou seja, a liberdade (comunicativa) é assegurada juridicamente. Em relação aos direitos de número 5 , ao contrário dos demais, que possuem um fundamento absoluto, estes possuem um fundamento relativo. Os direitos elencados de 1 a 4 são obrigatórios em todas as sociedades, dado que a racionalidade comunicativa e a estrutura do discurso os remete à legitimidade do ordenamento jurídico.

Para Habermas

[...] o código do direito não deixa outra escolha; os direitos de comunicação e de participação tem que ser formulados numa linguagem que permite aos sujeitos autônomos do direito escolher se e como vão fazer uso delas. Compete ao destinatário decidir se eles, enquanto autores, vão empregar a sua vontade livre, se vão passar por uma mudança de perspectivas que os faça sair do círculo dos próprios interesses e passar para o entendimento sobre normas capazes de receber o assentimento geral, se vão ou não fazer um uso público de sua liberdade comunicativa ${ }^{56}$.

Assim, para o direito fazer uso desta legitimidade ele não pode ser entendido de forma circular, a fim de buscar a legitimidade a partir do seu próprio domínio. O direito deve assegurar, por via da forma jurídica, o procedimento de formação discursiva da opinião. Essa perspectiva jurídica é confiantemente otimista, desde que seja capaz de garantir a ordem social (geralmente pautada pela regra).

Se na "Teoria da ação comunicativa" Habermas parte de uma tese de que o direito tem uma função instrumental, no capítulo III de "Faktizität und Geltung", denominado "Para a reconstrução do direito", ${ }^{57}$ Habermas parte da tese de que o direito tem uma função comunicativa de integração. Habermas estabelece uma relação entre FatoNorma em que não procura desprezar o elemento Valor para complementar a tridimensionalidade do direito. No entanto, persiste a dúvida:
REVISTA GRIFOS 293

${ }^{53}$ HABERMAS, J. Faktizität und Geltung, p. 157.

${ }^{54}$ HABERMAS, J. Faktizität und Geltung, p. 137.

${ }^{55}$ HABERMAS, J. Faktizität und Geltung, p. 163.

${ }^{56}$ HABERMAS, J. Faktizität und Geltung, p. 167.

${ }^{57}$ HABERMAS, J. Faktizität und Geltung, p. 112. 
${ }^{58}$ HABERMAS, J. Faktizität und Geltung, p. 102.

${ }^{59}$ HABERMAS, J. Faktizität und Geltung, p. 157.

${ }^{60}$ HABERMAS, J. Teoria de la acción comunicativa. p. 245. a legitimidade como legalidade é possível? A pergunta traduz Faktizität e Geltung por "eficácia” e "vigência”. A questão da relação eficáciavigência supõe uma outra questão, a da aceitação da norma. $\mathrm{O}$ direito como instrumento é útil porque garante uma força à norma: a eficácia da validez e, assim, a vigência se efetiva pela expectativa (ameaça) da sanção. A força da efetividade é a fusão de eficácia e vigência, como ocorre na religião, assim também no direito. Dessa forma, a norma é a simultânea efetividade pela coerção e realização da legitimação da validez, portanto, a positivação do direito não deixa de ser uma garantia.

A legalidade que se confunde com a legitimidade passa a assegurar a liberdade. Assim, a Teoria do agir comunicativo hipoteca a integração interna entre eficácia e vigência ${ }^{58}$, e o direito tem a função de integração social. Habermas entende que há necessidade de uma reconstrução do direito de modo que um sistema de ação possa assegurar o ordenamento legítimo enquanto componente social do mundo da vida. A integração social se aloja no direito como comunicação e estabelece uma ligação entre sistema e mundo da vida. Para Habermas há um paradoxo na origem da legitimidade e da legalidade, pois há uma ambivalência da vigência jurídica. A função do direito na sociedade moderna é a esperança de estabilidade, o que mostra uma relação interna com a força social integradora da ação comunicativa e se conclui pela presunção mútua entre a autonomia pública e privada com direitos humanos e soberania popular.

O direito é a disposição de legislar e legiferar como autonomias privada e pública. A tensão entre eficácia e vigência se refere à tensão entre positividade e legitimidade. O direito subjetivo deve se institucionalizar para ter fundamento político e desfazer o paradoxo da origem da legitimidade e da legalidade ${ }^{59}$. $\mathrm{O}$ médium do direito é entrelaçado com a instituição. Habermas entende que instituição é a norma jurídica que não pode ser suficientemente legitimada mediante o reclamo positivista a procedimentos. O Direito Constitucional, o Direito Penal e o Direito Processual precisam de uma justificação material, pois pertencem aos ordenamentos legítimos do mundo da vida e às normas informais de ação com o fundo do agir comunicativo.

Esse papel do aplicador da lei é discutido em confronto com o do legislador em "Faktizität und Geltung", quando Habermas tenta responder a questão: é possível a efetividade da coesão social na concepção de direito ou é o direito uma desconexão entre sistema e mundo da vida? Ao direito e à moral cabe a condição de apontar para um consenso racional sempre que a comunicação cotidiana falhar. É justamente em função deste diagnóstico que Habermas qualifica o direito e à moral como normas de ação. ${ }^{60}$ Para Habermas o sistema jurídico necessita de 
instituições básicas e eficazes capazes de legitimá-lo. Este, na verdade, é o papel desempenhado pelos direitos fundamentais (direitos humanos) e pelo princípio da soberania popular. Ambos ratificados pelas constituições do moderno estado de direito (HABERMAS, 2003, p. 116). Somente assim pode haver uma simbiose entre o sistema jurídico e a moralidade externa.

Mas como o direito pode se transformar em um médium de integração social? A partir da positivação do direito e na medida em que este assume a coordenação da ação, o risco de dissenso começa a diminuir. Este fenômeno ocasiona uma mudança no conceito de validade, pois "na validade jurídica a aceitação da ordem jurídica é distinta da aceitabilidade dos argumentos sobre os quais ela apóia a sua pretensão de legitimidade" (HABERMAS, 2003, p. 59). Na obra "Faktizität und Geltung: Beitrage zur Disskursstheorie des Rechts und desdemokratischen Rechtsstaats", Habermas aborda o tema da coesão social sob a ótica da complexidade histórica do direito. É bem verdade que não significa imputar um novo conceito de direito, mas da reconstrução da tradição histórica do direito, da peculiaridade dos gregos e da Themis, do direito da providência teológica, do jusnaturalismo teológico e antropológico, da revolução burguesa e da positivação do direito. Enfim, da modernidade e da subjetividade e da razão instrumental e do agir comunicativo. A proposta de substituição de um paradigma é a tarefa desencadeada por Habermas com o objetivo de invadir as esferas da cultura e do mundo da vida, utilizando-se de uma identidade sempre presente aos sujeitos: o direito.

O direito funciona como uma espécie de correia de transmissão que transporta, de forma abstrata, porém, impositiva, as estruturas de reconhecimento recíproco existentes entre conhecidos e em contextos concretos do agir comunicativo, para o nível das interações anônimas entre estranhos, mediadas pelo sistema. (HABERMAS, 2003, p. 308).

Uma das muitas questões que Habermas propõe para discutir em "Die Zukunnft der menschlichen Natur", "Auf den Weg zu einer liberalen eugenik?" e "Glauben und Wissen” é: “existem respostas pós-metafísicas para a questão sobre a 'vida correta'?” ${ }^{1} \mathrm{Na}$ "Mínima moralia" ${ }^{62}$ Adorno utiliza um refrão melancólico sobre a gaia ciência de Nietzsche como um mea culpa em relação à incapacidade de dar respostas à conduta da vida. É com esta observação que Habermas esboça um questionamento à biotecnologia em relação à forma como ela tem conduzido sua atuação: reflexões dispares e aforísticas originadas a partir da vida prejudicada não são suficientes para justificar um
${ }^{61}$ HABERMAS, J. Die Zukunnft der menschlichen Natur. Auf den Weg zu einer liberalen eugenik? p. 3.

62 "A ciência triste, da qual ofereço a meus amigos alguns fragmentos, refere-se a um campo que, durante muito tempo, foi considerado como o próprio da filosofia [...], a doutrina da vida correta." 

intervenção genética, assim como as velhas discussões acerca do aborto e da eutanásia solicitam novas abordagens.

\section{Referências}

ALEXY, R. A. A theory of legal argumentation: the theory of rational discourse as theory of legal justification. Oxford: Oxford University Press, 1989.

. A theory of practical discourse. In: BENHABIB, S; DALLMAYR,

F. The communicative ethics controversy. Cambridge: MIT, 1990. p. 166-167.

AUSIN, J. L. Quando dizer é fazer: palavras e ação. Porto Alegre: Artmed, 1990.

BRASIL. Código Civil. 46. ed. São Paulo: Saraiva, 2002. nado, 1988.

Constituição da República Federativa do Brasil. Brasília: Se-

DUTRA, D. J. V. Razão e consenso em Habermas: a teoria discursiva da verdade, da moral, do direito e da biotecnologia. Florianópolis: EdUFSC, 2005.

DWORKIN, R. Levando os Direitos a sério. São Paulo: Martins Fontes, 2002 .

DWORKIN, R. Life's Dominion: an argument about abortion, euthanasia and individual freedom. New York: Vintage Books, 1994.

HABERMAS, J. Técnica e ciência como Ideologia. Tradução Artur Morão. Lisboa: Edições 70, [s.d.]. Tradução de: Technik und Wissenschaft als Ideologie.

Conhecimento e interesse. Rio de Janeiro: Guanabara, 1987.

. Die Zukunft die menschilchen Natur. Auf den Weg zu einer liberalen Eugenik. Frankfurt: Suhrkamp, 2001.

Erkenntnis und interesse. Frankfurt: Suhrkamp, 1968.

Theorie dês Kommunikativen Handels. Frankfurt: Suhrkamp, 1983.

. Faktizität und Geltung. Diskurstheorie des Rechts und des demokratischen Rechtsstaats. Frankfurt: Suhrkamp; Hall, R.H., 1968.

. Teoria de la acción comunicativa. Madri: Taurus, 1987. 
- Teoria de la acción comunicativa: Complementos y estudios

previos. Madri: Catedra, 1994.

. Para a reconstrução do materialismo histórico. Tradução C. N. Coutinho. São Paulo: Brasiliense, 1990. Tradução de: Zur Rekonstruktion des Historischen Materialismus.

2002.

. A inclusão do outro: estudos de teoria política. São Paulo: Loyola,

. Comentários à Ética do Discurso. Lisboa: Instituto Piaget, 1991.

. O discurso filosófico da modernidade. Tradução M. Bernard. Lisboa: Dom Quixote, 1990. Tradução de: Der philosophische diskurs der moderne.

Direito e Democracia: entre facticidade e validade. v. I e II. Rio de Janeiro: Tempo Brasileiro, 2003.

. A constelação pós-nacional: ensaios políticos. Tradução M. Seligmann-Silva. São Paulo: Mundi, 2000.

. Escritos sobre moralidad y eticidad. Barcelona: Paidós, 1991.

. Consciência moral e agir comunicativo. Tradução G. A. Almeida. Rio de Janeiro: Tempo Brasileiro, 1989. Tradução de: Moralbewubtsein und Kommunikativen Handelns.

. Pensamiento postmetafísico. Tradução M. Jiménez Redondo. Madrid: Taurus, 1990. Tradução de: Nachmetaphysisches Denken.

. O futuro da natureza humana. São Paulo: Martins Fontes, 2004.

. Pensamento pós-metafísico: estudos filosóficos. Rio de Janeiro: Tempo Brasileiro, 1990.

. Perfiles filosófico-políticos. Tradução M. Jiménez Redondo. Madrid: Taurus, 1986. Tradução de: Philosophisch-politische Profile.

Mudança estrutural da esfera pública. Tradução F. R. Kothe. Rio de Janeiro: Tempo Brasileiro, 1984. Tradução de: Strukturwandel der Öffentlichkeit.

. Teoria e práxis. Tradução S. Más Torres e C. Moya Espí. 2. ed. Madrid: Tecnos, 1990. Tradução de: Theorie und práxis.

La lógica de las ciencias sociales. Tradução M. Jiménez Redondo.

Madrid: Tecnos, 1988. Tradução de: Zur Logik der Sozialwissenschaften. 
HEGEL, G. W. F. Fundamentos de la Filosofia del Derecho. Tradução C. Díaz. Edição de K. H. Ilting. Madrid: Ensayo, 1993. Tradução de: Grundlinien der Philosophie des Rechts.

KANT, I. La Metafísica de las Costumbres. Tradução A. C. Orts e J. C. Sancho. Madrid: Tecnos, 1989. Tradução de: Metaphysik der Sitten.

. Idéia de uma história universal de um ponto de vista cosmopolita. São Paulo: Brasiliense, 1986.

. Crítica da razão prática. Lisboa: Edições 70, 1997.

KELSEN, H. Teoria Pura o direito. Tradução J. B. Machado. São Paulo: Martins Fontes, 1991. Tradução de: Reine Rechtslehre.

RAWLS, J. Uma teoria da justiça. São Paulo: Martins Fontes, 2002.

ROANI. A. R. Moral e Direito: Kant versus Hegel. Passo Fundo: EdIFIBE, 2006.

WITTGENSTEIN, L. Investigações filosóficas. São Paulo: Abril Cultural, 1979.

\begin{abstract}
The objective of this text is to argue the proposal of Habermas of implementation of the right, once it is from this process that the legitimacy and the legality of the proper legal system derives. Modernity is an unfinished project in contrast of the post-modernity in which Habermas tries to structuralize the right from the context base of the comunicative reason. A reconstructive historical analysis of the right with emphasis on the coercive character and of this for a reconstruction of the right for the way of comunicative acting, thus to redesign the social effectiveness of the law system. Habermas aims to answer the following question: is it possible the effectiveness of the social cohesion in the conception of right or is the right a disconnection between law system and world of the life? For Habermas there is a latent necessity to reflect on these questions in conciliation with the idea of a jurisdiction, of a determination politics and moral capable to search one meaning for the determination of the correct life. Pluralism and the multiculturalism are realities in the way of a justice that, each time more, needs the participation of its actors to acquire legitimacy and validity (acceptance). This proposal of change in the recital of the right evoked by Habermas promotes an overturn in the way to articulate the right and, thus, the right can accomplish the great aspiration of the humanity, namely, the effectiveness of the freedom.
\end{abstract}

Keywords: Habermas, right, discourse theory. 